\title{
A Co-Integration Analysis Between Electricity Consumption and Economic Development in Hebei Province
}

\author{
Huiru Zhao', Yaowen Fan $^{1}$, Nana $\mathrm{Li}^{1}$, Fuqiang $\mathrm{Li}^{2}$, Yuou $\mathrm{Hu}^{2}$ \\ ${ }^{1}$ School of Economics and Management, North China Electric Power University, Beijing, China \\ ${ }^{2}$ North China Grid Company Limited, Beijing, China
}

Email address:

nancyli1007@163.com (Nana Li)

\section{To cite this article:}

Huiru Zhao, Yaowen Fan, Nana Li, Fuqiang Li, Yuou Hu. A Co-Integration Analysis Between Electricity Consumption and Economic Development in Hebei Province. International Journal of Energy and Power Engineering. Special Issue: Current Energy Issues in China. Vol. 4, No. 4-1, 2015, pp. 1-6. doi: 10.11648/j.ijepe.s.2015040401.11

\begin{abstract}
Electricity is a convenient and clean energy which can provide strong support for the development of all walks of life. The power development should maintain coordination with the regional economic development, in which power development may advance sometimes. Hebei province is a typical resource-based area in China, and its power consumption is closely related to economic development, which makes it important to study the relationship between electricity and economic development in Hebei. In order to select the economic factors affecting electricity demand, the gray correlation analysis is used to analyse the correlation among different factors. And then, a long-term equilibrium model between electricity consumption and economic factors is proposed through co-integration analysis. The analysis result showed that the electricity consumption, GDP, the level of residential consumption, efficiency levels and economic structures have a long-run equilibrium relationship in Hebei Province, in which the economic structure has the strongest impact on the electricity consumption, followed by GDP, energy consumption intensity and the residential consumption level. Currently, the impact of the economic restructuring on electricity demand in Hebei cannot be overlooked. Furthermore, this model can be used to give a reference to Hebei Electric Power Planning.
\end{abstract}

Keywords: Electricity Consumption, Economic Development, Co-Integration Theory

\section{Introduction}

In recent years, Hebei has made considerable progress in economy through taking advantage of the unique natural resources, geographical location and other aspects. The GDP of Hebei has reached 2.83 trillion yuan in 2013 and the average annual growth rate from 1978 to 2013 is $10.78 \%$.Meanwhile, Hebei's economic development is inseparable from the rapid growing electricity consumption. In 2012, Hebei's total electricity consumption has reached 307.773 billion $\mathrm{kWh}$, accounting for 6.21 percent of China's power consumption and its per capita electricity consumption is $4223.01 \mathrm{kwh}$.

In recent years, as the non-stationary of the time series of electricity and economy, the co-integration theory related with non-stationary time series has become the main method for the relationship analysis between power and economy. Engel-Granger method is implied to estimate the relationship between the US energy and economy in 1974-1990[1]. This method has also been applied to the Group of Seven and 16 newly industrialized countries except China[2]. Analysis of the relationship between the Greek GDP and energy consumption in 1960-1996 has been made using vector error correction model[3]. In the related researches for China, Johansen Method has been used for Taiwan in 1955-1993 and 1954-1997 [4-5], this method has also been used to analyse the relationship between electricity consumption and economic development between 1952-2001 and 1970-2001 in China[6-7]. Hebei is located in north central China, and it is a typical resource-based province whose electricity consumption condition is quite different with whole China obviously. Thus this paper uses gray relational analysis model to select economic factors which affect the electricity demand most in Hebei. Then co-integration analysis model has been proposed to illustrate the relationship between electric demand and economic growth which could be helpful for future electricity planning. 


\section{Theory and Methodology}

\subsection{Grey Correlation Analysis}

The basic idea of gray correlation analysis is to determine the degree of association between factors based on the similarity between the curve. Grey correlation analysis usually compares the data series which reflects changes in each factor. The correlation level between factors is judged by the degree of association which is obtained by comparing the association between factor curves. There are six steps in the gray correlation analysis:

(1)Determine the reference sequence and comparative sequence $X_{0}=\left[X_{0}(1), X_{0}(2), \cdots X_{0}(n)\right] \quad$ is the reference sequence and $X_{i}=\left[X_{i}(1), X_{i}(2), \cdots X_{i}(n)\right](i=1,2, \cdots, l) \quad$ is $\quad$ the comparative sequence.

(2)Calculate sequence $X_{0}$ and gray absolute correlation $\phi_{0 i}$ of sequence $X_{i}$.

Gray absolute correlation is only associated with geometric shape of sequence $X_{0}$ and $X_{i}$, which has nothing to do with their relative location. The specific formula is shown as follows:

$$
\phi_{0 i}=\frac{1+\left|S_{0}\right|+\left|S_{i}\right|}{1+\left|S_{0}\right|+\left|S_{i}\right|+\left|S_{i}-S_{0}\right|}
$$

Where, $k=1,2, \cdots n-1$.

$$
\begin{array}{r}
\left|S_{0}\right|=\left|\sum_{k=2}^{n-1} X_{0}^{0}(k)+\frac{1}{2} X_{0}^{0}(n)\right| \\
\left|S_{i}\right|=\left|\sum_{k=2}^{n-1} X_{i}^{0}(k)+\frac{1}{2} X_{i}^{0}(n)\right| \\
\left\{\begin{array}{l}
X_{0}^{0}(k)=X_{0}(k)-X_{0}(1) \\
X_{i}^{0}(k)=X_{i}(k)-X_{i}(1)
\end{array}\right.
\end{array}
$$

(3) Calculate the gray relative correlation $\pi_{0 i}$ between $X_{0}$ and $X_{i}$.

Gray relative correlation denotes the relationship between the changing rate of sequence with respect to the starting point. Namely, the closer the changing rate of $X_{0}$ and $X_{i}$, the greater the gray relative correlation is.

$$
\pi_{0 i}=\frac{1+\left|S_{0}^{\prime}\right|+\left|S_{i}^{\prime}\right|}{1+\left|S_{0}^{\prime}\right|+\left|S_{i}^{\prime}\right|+\left|S_{i}^{\prime}-S_{0}^{\prime}\right|}
$$

Where, $k=1,2, \cdots n-1$.

$$
\begin{aligned}
& \left|S_{0}^{\prime}\right|=\left|\sum_{k=2}^{n-1} X_{0}^{0^{\prime}}(k)+\frac{1}{2} X_{0}^{0^{\prime}}(n)\right| \\
& \left|S_{i}^{\prime}\right|=\left|\sum_{k=2}^{n-1} X_{i}^{0^{\prime}}(k)+\frac{1}{2} X_{i}^{0^{\prime}}(n)\right| \\
& \left\{\begin{array}{l}
X_{0}^{0^{\prime}}(k)=\frac{X_{0}(k)}{X_{0}(1)} \\
X_{i}^{0^{\prime}}(k)=\frac{X_{i}(k)}{X_{i}(1)}
\end{array}\right.
\end{aligned}
$$

(4) Calculate the grey synthetic correlation degree $\rho_{0 i}$ between $X_{0}$ and $X_{i}$.

$$
\rho_{0 i}=\theta \phi_{0 i}+(1-\theta) \pi_{0 i}
$$

Where, $\theta \in[0,1]$, in general, $\theta$ can be 0.5 .

(5) Select the key factors according to the calculation results.

Determine the threshold value for $\rho$ and select the key factors. If synthetic correlation degree $\rho_{0 i}$ is bigger than $\rho$, $X_{i}$ should be the key indicator.

\subsection{Co-Integration Analysis}

Co-integration was firstly put forward by Granger in 1981 and Engle and Granger proposed the theorem and its concrete operational framework [8-9].In general, yt $\sim \mathrm{I}(\mathrm{d})$ shows that yt becomes stationary after $\mathrm{d}$ times differencing. If variables are all I(1), their linear combination o usually satisfies I(1). Further, stationary linear combination series can be called co-integrated which implies the existence of a long-term equilibrium relationship between the variables.

When examine the stationary of each history series, Augmented Dickey and Fuller(ADF) approach is usually used[10]. ADF test is an improved form of DF (Dickey and Fuller) unit root test in which the statistical test function is presented as:

$$
\Delta X_{t}=\alpha+\beta t+\delta X_{t-1}+\sum_{i=1}^{p} \theta_{i} \Delta X_{i-1}+\varepsilon_{t}
$$

Where $\varepsilon_{t}$ is the random error. It is an independent identically distributed (i.i.d.) white noise process. For a given level of significance, the time series is stable if the ADF test value is less than the critical value.

The next step after the unit root test is JJ (Johansen and Juselius) co-integration test. If two or more variables are $\mathrm{I}(\mathrm{d})$, their linear combination is co-integration, which can be defined as said long-run equilibrium relationship[11]. There are two ways to test the co-integration: TRACE and MAX are commonly two output results in this test. 


\section{Quantitative Analysis of the Relationship Between Power and Economy in Hebei}

Studies have shown that there is a certain relationship between the electricity demand and economy development, which has been demonstrated by scholars [6-7]. But the economic factors impacting the electricity demand have not gotten consistent conclusions. Economic growth, industrial structure, population, urbanization rate, export and technological advance may affect the electricity demand. Therefore, the gray correlation model has been used to select the economic factors which affect the electricity demand most. The variables are picked and defined as follows.

Electricity Consumption (Q).The total electricity consumption of Hebei Province in 2012 has reached 307.773 billion $\mathrm{kWh}$, accounting for 6.21 percent of China's power consumption, and accounting for $0.02 \%$ of world electricity consumption. Meanwhile, per capita electricity consumption of Hebei has reached 4223.01 kwh. Hebei Electric Power Consumption data is shown as Figure 1.

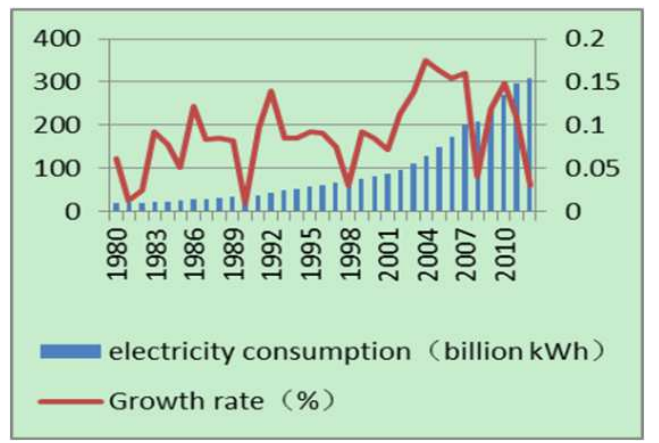

Figure 1. The electricity consumption in Hebei.

Gross domestic product (GDP).GDP refers to the gross domestic product in Hebei, which reflects the level of economic development. The GDP of Hebei is 2.657501 trillion yuan in 2012, accounting for 5.12 percent of China's GDP. The data of GDP is shown as Figure2.

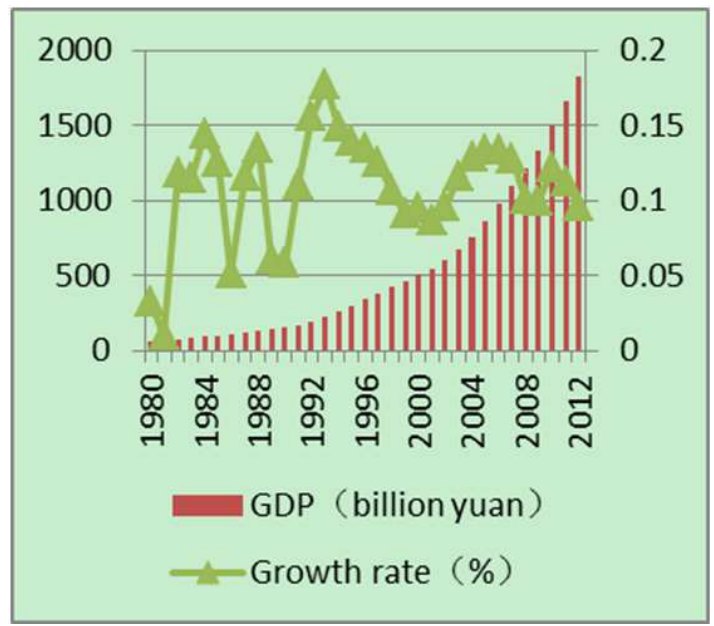

Figure 2. The GDP in Hebei.
Residential consumption level (RCL). RCL reflects the living standards of local residents. When in economic expansion, RCL is considerably high. From 1978 to 2012, the level of consumption in Hebei province increase with the growth of GDP, and reached 10,749 yuan (nominal value) in 2012. The data is shown as Figure 3.

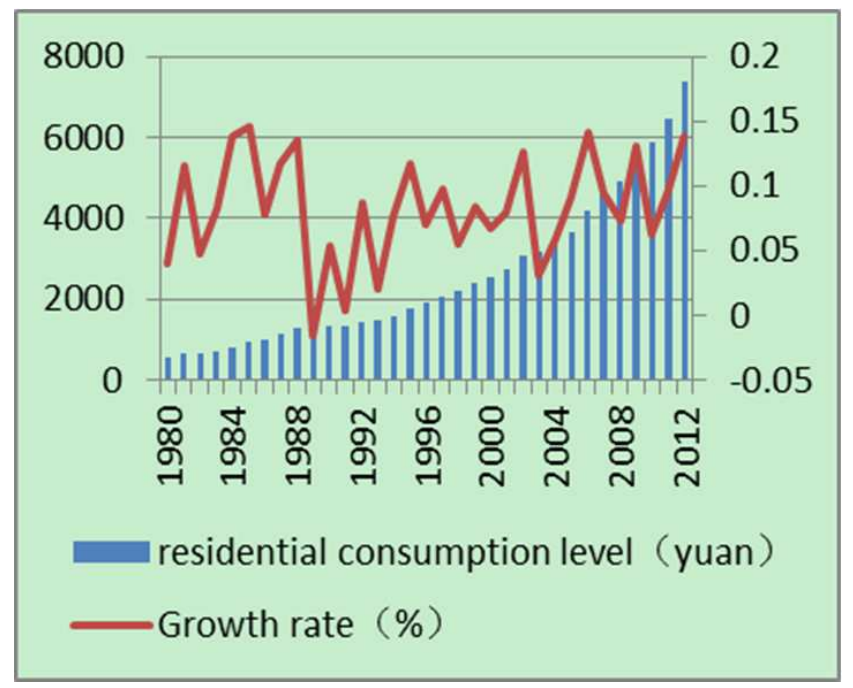

Figure 3. The residential consumption level in Hebei.

Efficiency level (EF). EF refers to energy consumption intensity. In 1980-2011, the energy consumption intensity of Hebei is reduced from 5.00 tons of standard coal to 1.66 tons of standard coal. The data is shown as Figure 4.

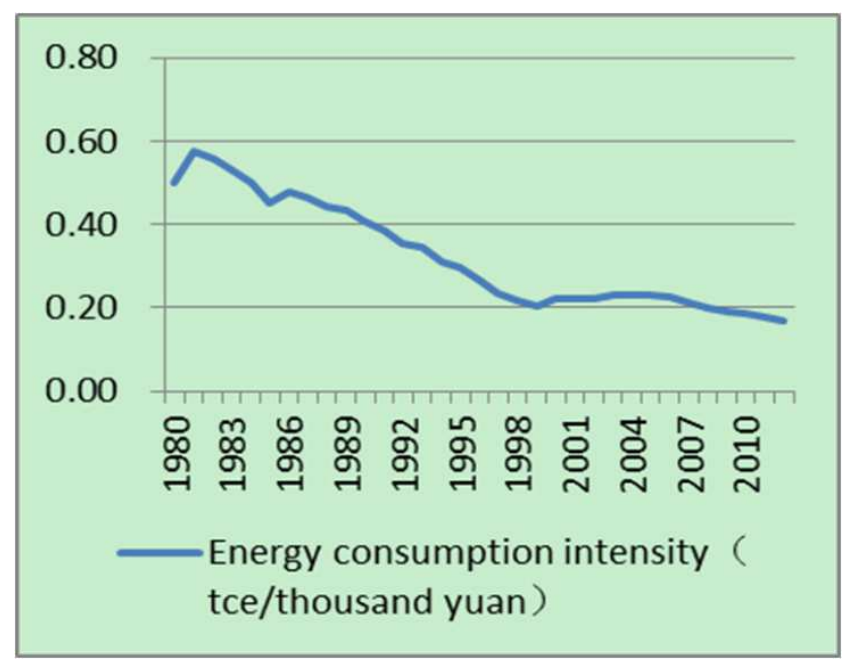

Figure 4. The energy consumption intensity in Hebei.

Economic structure (STRU).STRU refers to the tertiary industry proportion of GDP. The proportion of the first industry is relatively small while the proportion of the secondary industry is relatively stable with the highest proportion. Compared with 1978, the proportion of primary industry dropped from $28.52 \%$ to $12.37 \%$ in 2012 , the proportion of secondary industry has remained at about $50 \%$ level, the proportion of tertiary industry increased to $21.02 \%$ from $35.47 \%$ in 2012 . The data is shown as Figure 5. 


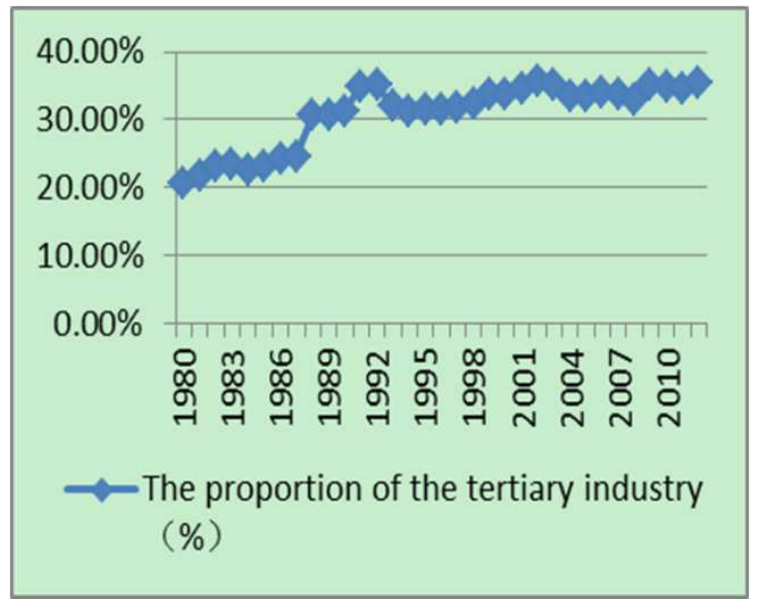

Figure 5. The proportion of the tertiary industry.

\section{Model and Results}

\subsection{The Gray Correlation Analysis}

To fully characterize the level of economic development, the GDP, residential consumption level, exports level, industry structure (tertiary proportion) and technical progress (energy intensity) are chosen to select the key factors based on the gray correlation analysis. Data interval is 1980-2012 and the results are shown in Table 1.

Table 1. Gray correlation analysis result

\begin{tabular}{lll}
\hline Indicators & Correlation & Rank \\
\hline GDP & 0.727617259 & 2 \\
RCL & 0.813460967 & 1 \\
EXP & 0.700820384 & 5 \\
STRU & 0.758933167 & 2 \\
EF & 0.721373249 & 4 \\
\hline
\end{tabular}

When the indicators increase, the co-integration model requires more data. Also, spreadsheet shows that total exports in multivariate model has little effect on electricity consumption, so the following variables are selected to build the co-integration model: GDP, the level of consumption, industrial structure, and energy intensity.

In order to eliminate fluctuations and heteroscedasticity, part of the data are processed logarithmic.

\subsection{Results of Unit-Root Tests}

To check the stationary of variables used in the model, ADF test is adopted in this paper, results are shown in Table 2.

Table 2. Unit root test of variables

\begin{tabular}{llll}
\hline Series & Trends and intercept & ADF value & P-Value \\
\hline $\ln G D P$ & $(\mathrm{C}, \mathrm{C}, 3)$ & -2.492644 & 0.3290 \\
$\Delta \ln G D P$ & $(\mathrm{C}, \mathrm{C}, 5)$ & -4.994957 & $0.0024^{* * *}$ \\
$\ln \mathrm{C}$ & $(\mathrm{C}, \mathrm{C}, 0)$ & -1.913891 & 0.6240 \\
$\Delta \ln Q$ & $(\mathrm{C}, \mathrm{C}, 0)$ & -3.828068 & $0.0283^{* *}$ \\
$\ln R C L$ & $(\mathrm{C}, \mathrm{C}, 0)$ & -1.913891 & 0.6240 \\
$\Delta \ln R C L$ & $(\mathrm{C}, \mathrm{C}, 0)$ & -3.828068 & $0.0283^{* *}$ \\
$\ln S T R U$ & $(\mathrm{C}, \mathrm{C}, 0)$ & -1.868447 & 0.6472 \\
$\Delta \ln S T R U$ & $(\mathrm{C}, \mathrm{C}, 5)$ & -3.744667 & $0.0369^{* *}$ \\
$\ln E F$ & $(\mathrm{C}, \mathrm{C}, 2)$ & -2.107893 & 0.5208 \\
$\Delta \ln E F$ & $(\mathrm{C}, \mathrm{C}, 0)$ & -5.266468 & $0.0009^{* * *}$ \\
\hline
\end{tabular}

$\Delta$ indicates the first difference of a time series. $* * * * *$ and $*$ indicate results are statistically significant at $1 \%, 5 \%$ and $10 \%$ levels, respectively.

As shown in Table 2, the null hypothesis of a unit root could not be rejected. Results indicate that the null hypothesis of a unit root was significantly rejected in the second difference. Therefore we conclude that all five variables are at first-difference stationary, which fulfills the requirements of the co-integration test.

\subsection{Select the Lag Intervals for VAR model}

We need to construct an unrestricted vector autoregressive (VAR) that is composed of $\operatorname{lnQ}, \operatorname{lnGDP}, \mathrm{STRU}, \operatorname{lnRCL}$, and $\mathrm{EF}$ to analyze the co-integration relationship among the variables. Therefore, we need to select the optimal lag order. In this paper, we choose a lag of 2 by using the Schwarz information criterion (SC), sequential modified LR test (LR), Final prediction error (FPE), Akaike information criterion (AIC) and Hannan-Quinn information criterion (HQ).As shown in table 3 , lag interval of 2 is conformably chosen by the criteria of LR, AIC and HQ.

Table 3. The lag intervals

\begin{tabular}{lllllll}
\hline Lag & LogL & LR & FPE & AIC & HQ & -9.60 \\
0 & 157.37 & NA & 346.14 & $3.70 \mathrm{e}-11$ & -9.83 & -9.76 \\
1 & 371.98 & $45.44^{*}$ & $1.85 \mathrm{e}-16$ & -22.06 & $-20.68 *$ \\
2 & 407.19 & $1.10 \mathrm{e}-16^{*}$ & $-22.72 *$ & -20.18 & $-21.9 *$ & \\
\hline
\end{tabular}

*indicates lag order selected by the criterion.

\subsection{Johansen Co-Integration Test}

We use trace statistic and the maximum eigenvalue statistic to estimate the number of co-integration relationships and the normalized co-integrating coefficient. The results are shown as table 4 . 
Table 4. Co-integration test results

\begin{tabular}{llll}
\hline Hypothesized No. of CE(s) & Eigenvalue & Trace Statistic & 0.05Critical Value \\
\hline None & 0.859236 & 104.7236 & 69.81889 \\
At most 1 & 0.486274 & 43.94271 & 47.85613 \\
At most 2 & 0.421657 & 23.29472 & 29.79707 \\
At most 3 & 0.163145 & 6.319511 & 15.49471 \\
At most 4 & 0.025422 & 0.798281 & 3.841466 \\
Hypothesized No. of CE(s) & Hypothesized No. of CE(s) & Eigenvalue & Trace Statistic \\
None & 0.859236 & 60.78087 & 33.87687 \\
At most 1 & 0.486274 & 20.64799 & 27.58434 \\
At most 2 & 0.421657 & 16.97521 & 21.13162 \\
At most 3 & 0.163145 & 5.521231 & 0.2319 \\
At most 4 & 0.025422 & 0.798281 & 0.3716 \\
\hline
\end{tabular}

Trace method and the max eigenvalue method show the presence of a co-integration relationship between the variables, indicating that GDP, consumer level (RCL), industry structure (STRU) ,energy intensity(EF)hold a long-term stable relationship with electricity consumption.

\subsection{The Long-Term Equilibrium Model of Economy and Electricity Demand}

The Co-integration coefficients in time interval 1980-2012 is shown as table 5 .

Table 5. Co-integration coefficients

\begin{tabular}{lcccc}
\hline Co-integrating Equation(s): & \multicolumn{1}{c}{ Log likelihood } & \multicolumn{4}{l}{$\mathbf{4 6 4 . 3 3 0 3}$} \\
\hline \multicolumn{2}{l}{ Normalized co-integrating coefficients (standard error in parentheses) } & & \\
$\ln Q$ & $\ln G D P$ & $\ln S T R U$ & $\ln R C L$ & $\ln E F$ \\
1.000000 & -0.836429 & 0.6096 & -0.5197 & -0.6689 \\
& $(0.09965)$ & $(0.29864)$ & $(0.11907)$ & $(0.08141)$ \\
\hline
\end{tabular}

$\ln Q=0.84 \ln G D P+0.51 \ln R C L-0.61 \ln S T R U+0.67 \ln E F$

The results show that $1 \%$ of GDP growth can cause $0.84 \%$ growth in electricity demand, 1 point change in tertiary industry proportion accounted for $0.61 \%$ reduction in power consumption, energy consumption intensity increases 1 percent, electricity consumption increase $0.67 \%$. The impact of changes in the GDP is maximum among all key factors affecting the demand for electricity.

\section{Conclusion and Policy Implications}

Through qualitative analysis and gray correlation analysis, GDP, the residential consumption level, industrial structure, technological advancement have an impact on electricity demand in Hebei Province. The co-integration analysis shows that long term equilibrium relationship among GDP, the residential consumption level, industrial structure, energy intensity (EF) is exist. $1 \%$ of GDP growth can cause $0.84 \%$ growth in electricity demand, 1 point change in tertiary industry proportion accounted for $0.61 \%$ reduction in power consumption, energy consumption intensity increases 1 percent, electricity consumption increase $0.67 \%$. The impact of changes in GDP is maximum in all the factors affecting the demand for electricity. The model also shows when future electricity demand forecasting is being made, economic growth, economic structure, living standards and technical progress factors should all be take into consideration comprehensively and the impact of structural changes needs extra attention.

\section{Acknowledgments}

This study is supported by the Humanity and Social Science project of the Ministry of Education of China (Project number: 11YJA790217), the National Natural Science Foundation of China (Project number: 71373076), and Science and Technology Project of State Grid Corporation of China (Contract number: SGHB0000DKJS1400116).

\section{References}

[1] Stern D I. Energy and Growth in the USA: multivariate approach[J]. Energy Economics, 15(2), pp.137-150,1993.

[2] Soytas U, Sari R. Energy consumption and GDP: causality relationship in G7 countries and emerging markets[J]. Energy Economics, 5(1), pp.33-37, 2003.

[3] Hondroyiannis G, Lolos S, Papapetrou E. Energy consumption and economic growth: assessing the evidence from Greece[J]. Energy Economics, 24(4), pp.319-336, 2002.

[4] Cheng B L, Lai T W. An investigation of co-integration and causality between energy consumption and economic activity in Taiwan [J]. Energy Economics, 19(4), pp.435-444, 1997.

[5] Yang H Y. A Note on the causal relationship between energy consumption and GDP in Taiwan [J]. Energy Economics.22(4), pp.309-317, 2000.

[6] Lin Boqiang. Structural change, efficiency improvement and electricity demand forecasting[J]. Economic Research, 38(5), pp. 57-65, 2003. 
[7] Shiu A, Lam P L. Electricity consumption and economy growth in China [J]. Energy Policy, 32(1), pp. 47-54, 2004.

[8] Granger C.W.J. Some properties of time series data and their use in econometric model specification [J]. Journal of econometrics, 16(1), pp. 121-130, 1981.

[9] Engle R F, Granger C W J. Co-integration and error correction: representation, estimation, and testing $[\mathrm{J}]$. Econometrica: journal of the Econometric Society, pp. 251-276, 1987.
[10] Dickey D A, Fuller W A. Likelihood ratio statistics for autoregressive time series with a unit root $[\mathrm{J}]$. Econometrica: Journal of the Econometric Society, pp.1057-1072, 1981.

[11] Johansen S, Juselius K. Maximum likelihood estimation and inference on co-integration - with applications to the demand for money [J]. Oxford Bulletin of Economics and statistics, 52(2), pp. 169-210, 1990. 